\title{
Magnesium sulphate and amiodarone prophylaxis for prevention of postoperative arrhythmia in coronary by-pass operations Osman Tiryakioglu*1, Sinan Demirtas' ${ }^{1}$, Hasan Ari², Selma Kenar Tiryakioglu², Kagan Huysal ${ }^{3}$, Ozer Selimoglu${ }^{4}$ and Ahmet Ozyazicioglu ${ }^{1}$
}

Address: ${ }^{1}$ Bursa Yuksek İhtisas Education and Research Hospital, Department of Cardiovascular Surgery, Bursa, Turkey, ${ }^{2}$ Bursa Yuksek İhtisas Education and Research Hospital, Department of Cardiology, Bursa, Turkey, ${ }^{3}$ Bursa Yuksek İhtisas Education and Research Hospital, Department of Biochemistry, Bursa, Turkey and ${ }^{4}$ Medical Park Hospital, İstanbul, Turkey

Email: Osman Tiryakioglu* - tiryaki64@hotmail.com; Sinan Demirtas - sinandemirtas78@hotmail.com; Hasan Ari - hasanari03@yahoo.com; Selma Kenar Tiryakioglu - selmatiryaki@msn.com; Kagan Huysal - khuysal@yahoo.com; Ozer Selimoglu - ozerselimoglu@hotmail.com;

Ahmet Ozyazicioglu - violinahmet@hotmail.com

* Corresponding author

Published: 20 February 2009

Journal of Cardiothoracic Surgery 2009, 4:8 doi:10.1186/1749-8090-4-8
Received: 18 September 2008

Accepted: 20 February 2009

This article is available from: http://www.cardiothoracicsurgery.org/content/4/I/8

(c) 2009 Tiryakioglu et al; licensee BioMed Central Ltd.

This is an Open Access article distributed under the terms of the Creative Commons Attribution License (http://creativecommons.org/licenses/by/2.0), which permits unrestricted use, distribution, and reproduction in any medium, provided the original work is properly cited.

\begin{abstract}
Background: The aim of this study was to investigate the use of prophylactic magnesium sulphate and amiodarone in treating arrhythmias that may occur following coronary bypass grafting operations.
\end{abstract}

Methods: The study population consisted of 192 consecutive patients who were undergoing coronary artery bypass grafting (CABG). Sixty-four patients were given $3 \mathrm{~g}$ of magnesium sulphate (MgSO4) $\left[20 \mathrm{ml}=24.32 \mathrm{mEq} / \mathrm{L} \mathrm{Mg}^{+2}\right]$ in $100 \mathrm{cc}$ of isotonic $0.9 \%$ solution over 2 hours intravenously at the following times: 12 hours prior to the operation, immediately following the operation, and on postoperative days I, 2, and 3 (Group I). Another group of 64 patients was given a preoperative infusion of amiodarone (I $200 \mathrm{mg}$ ) on first post-operative day (Group 2). After the operation amiodarone was administered orally at a dose of $600 \mathrm{mg} /$ day. Sixty-four patients in group 3 (control group) had $100 \mathrm{cc}$. isotonic $0.9 \%$ as placebo, during the same time periods.

Results: In the postoperative period, the magnesium values were significantly higher in Group I than in Group 2 for all measurements. The use of amiodarone for total arrhythmia was significantly more effective than prophylactic treatment with magnesium sulphate $(p=0.015)$. There was no difference between the two drugs in preventing supraventricular arrhythmia, although amiodarone significantly delayed the revealing time of atrial fibrillation $(p=0.026)$. Ventricular arrhythmia, in the form of ventricular extra systole, was more common in the magnesium prophylaxis group. The two groups showed no significant differences in other operative or postoperative measurements. No side effects of the drugs were observed.

Conclusion: Prophylactic use of magnesium sulphate and amiodarone are both effective at preventing arrhythmia that may occur following coronary by-pass operations. Magnesium sulphate should be used in prophylactic treatment since it may decrease arrhythmia at low doses. If arrhythmia should occur despite this treatment, intervention with amiodarone may be preferable. 


\section{Background}

Postoperative rhythm disorders are a serious complication of open-heart surgery. The incidence of postoperative supraventricular arrhythmias has been reported to be 11$54 \%$, and the incidence of ventricular arrhythmia to be $1.8-13 \%$. [1]. Arrhythmias are frequently seen during the first 48 hours following open-heart surgery, necessitating effective postoperative monitoring. Knowledge of what causes the development and progression of arrhythmia in a postoperative patient may allow us to reduce the use of pharmacological and electrical procedures aimed at reducing the ventricular rate or ensuring normal sinus rhythm.

The large majority of arrhythmia cases in coronary artery bypass surgery (CABG), except insufficient revascularization, can be controlled by electrical cardio versions. However, most medications currently used include betablockers or negative inotropics and some of them increase myocardial oxygen consumption as a side effect. The decrease in the concentrations of ions such as potassium and magnesium during the postoperative period is an important factor in most of the cases of arrhythmia that do not have organic causes (e.g. insufficient revascularization and graft thrombosis). Identifying and detecting these ionic imbalances may protect the heart from the side effects of anti-arrhythmia treatments. Among the physiological ions, magnesium plays an important role in preserving cardiac rhythm by stabilizing membrane function [1-3].

The aim of our study was to compare the effects of magnesium sulphate and amiodarone in the prevention and treatment of ventricular and supraventricular arrhythmia following CABG.

\section{Methods}

The study was performed on 192 patients who had undergone successful CABG. The local Ethics Committee approved of the study, and personal informed consent was taken.

Sixty-four patients were given $3 \mathrm{~g}$ of magnesium sulphate $(\mathrm{MgSO} 4)\left[20 \mathrm{ml}=24.32 \mathrm{mEq} / \mathrm{L} \mathrm{Mg}^{+2}\right]$ in $100 \mathrm{cc}$ of isotonic $0.9 \%$ solution intravenously for 2 hours at the following times: 12 hours prior to the operation, immediately following the operation, and on postoperative days 1, 2, and 3 (Group 1). The other group of 64 patients was given a preoperative amiodarone infusion of $1200 \mathrm{mg}$ on the postoperative first day (Group 2). This dose was followed by an oral dose of $600 \mathrm{mg} /$ day. Sixtyfour patients in group 3 (control group) had $100 \mathrm{cc}$. isotonic $0.9 \%$ as placebo, during the same time periods.
During the same postoperative period, $\mathrm{K}^{+}$replacements [in the form of glucose-insulin-potassium (GIK) solution (500 cc of $5 \%$ dextrose +90 meq $\mathrm{K}^{+}+12 \mathrm{U}$ crystallized insulin)] and $\mathrm{Ca}^{+2}$ replacements ( $1 \mathrm{~g}$ Ca-gluconate in 100 cc of isotonic $0.9 \%$ solution) were administered in order to maintain a $\mathrm{K}^{+}$concentration of at least $3.5-5.5 \mathrm{meq} / \mathrm{L}$, and a $\mathrm{Ca}^{+2}$ concentration of at least $8-9 \mathrm{meq} / \mathrm{L}$. In order to standardize the groups, patients were grouped based on the following parameters: age, gender, use of calcium channel blocker, use of beta-blocker, presence of diabetes, presence of renal disorder, presence of chronic obstructive pulmonary disease (COPD), history of non-cardiac operations, history of myocardial infarction (MI), classification of New York Heart Association (NYHA), end diastolic pressure (EDP), cross-clamp time, cardiopulmonary bypass durations, and coronary bypass count (Table 1 ).

Anti-arrhythmia drugs used in the preoperative period were halted 24 hours before the operation. Twelve derivation electrocardiographies of the patients were taken on the morning of the operation day and patients showing arrhythmia or ischemia were excluded from the study.

\section{Operational procedure}

Midazolam $(0.03 \mathrm{mg} / \mathrm{kg})$, hypnomidate $(0.3 \mathrm{mg} / \mathrm{kg})$, phentanyl $(5 \mu \mathrm{g} / \mathrm{kg})$, and pancuronium bromide $(0.1 \mathrm{mg} /$ $\mathrm{kg}$ ) were used for anesthesia. When continuation was needed, $5 \mu \mathrm{g} / \mathrm{kg}$ of phentanyl and $0.05 \mathrm{mg} / \mathrm{kg}$ of pancuronium or vecuronium bromide were used.

All patients were subjected to standard median sternotomy. The left internal mammarian artery (LIMA) and vena saphena magna from the lower extremity were dissected and prepared. The arteria radialis was used for two cases.

The LIMA graft was anastomosed to the left anterior descending coronary artery (LAD) in all cases. With the arterial cannulation from the aorta ascending and twostage venous cannulation from right atrial auricular, the cardio-pulmonary bypass was introduced. A cardioplegia cannula was placed in the aortic root and all the patients were given cardioplegia by the anterograde way. A supply of oxygenated blood was prepared throughout the operation, and the cardioplegic fluid prepared in this way was administered using a "warm induction" procedure in order to cause diastolic arrest. A total volume of $10 \mathrm{ml} / \mathrm{kg}$ of cardioplegic fluid at a temperature of $37^{\circ} \mathrm{C}$ was introduced into the heart through the aortic root. Cardioplegia was periodically continued for periods of 15 minutes after cooling. Warming was initiated as the LIMA-LAD anastomosis was performed. Before the cross-clamp was removed, a final dose of "hot shot" cardioplegic fluid (10 $\mathrm{ml} / \mathrm{kg}, 37^{\circ} \mathrm{C}$ ) was delivered in order to control reperfusion and prevent any reperfusion damage. Moderate 
Table I: Preoperative and demographic characteristics of the patients in the study sample.

\begin{tabular}{|c|c|c|c|c|}
\hline & Group I (Magnesium, $n=64$ ) & Group 2 (Amiodarone, $\mathrm{n}=64$ ) & Group 3 (Control, $\mathrm{n}=64)$ & $P$ value \\
\hline Age (years) & $58 \pm 8$ & $61 \pm 6$ & $57.6 \pm 8.8$ & NS \\
\hline $\operatorname{Sex}(M / F)$ & $40 / 24$ & $42 / 22$ & $52 / 8$ & NS \\
\hline History of MI & $32(50 \%)$ & $30(47 \%)$ & $30(47 \%)$ & NS \\
\hline Hypertension & $23(36 \%)$ & $21(33 \%)$ & $23(36 \%)$ & NS \\
\hline Smoking & $23(36 \%)$ & $16(25 \%)$ & $23(36 \%)$ & NS \\
\hline COPD & $7(11 \%)$ & $8(12.5 \%)$ & $8(12.5 \%)$ & NS \\
\hline PTCA-Stent & $4(6.2 \%)$ & $6(9.4 \%)$ & $4(6.2 \%)$ & NS \\
\hline Preoperative use of beta blocker & $21(33 \%)$ & $23(36 \%)$ & $21(33 \%)$ & NS \\
\hline BSA & $1.79 \pm 0.2$ & $1.78 \pm 0.3$ & $1.78 \pm 0.3$ & NS \\
\hline $\operatorname{LVEDP}(\mathrm{mmHg})$ & $13.6 \pm 4.2$ & $16.9 \pm 6.5$ & $14.6 \pm 4.4$ & NS \\
\hline Left ventricle EF (mean \%) & $45 \pm 4$ & $43 \pm 3$ & $44 \pm 4$ & NS \\
\hline Diabetes Mellitus & $20(31 \%)$ & $18(28 \%)$ & I8 (28\%) & NS \\
\hline
\end{tabular}

MI, myocardial infarction; COPD, chronical obstructive pulmonary disease; NYHA, New York Heart Association; PTCA, percutan transluminal coronary angioplasty; BSA, body surface area; LVEDP, left ventricle end diastolic pressure; NS, not significant $(p>0.05)$.

hypothermia $\left(28^{\circ} \mathrm{C}\right)$ was maintained throughout the operation.

None of the patients in any group received any antiarrhythmia protocol other than those described.

Magnesium blood ion analysis: plasma $\mathrm{Mg}^{+2}$ levels were determined by spectrophotometric analysis of venous blood samples taken immediately after the operation and on postoperative days 1,2 , and 3 . Total $\mathrm{Mg}^{+2}$ levels were recorded. At the same time, levels of $\mathrm{Na}^{+}, \mathrm{K}^{+}$, and $\mathrm{Ca}^{+2}$ were also determined, and their insufficiencies replaced in the patients.

Liver function tests (SGOT, SGPT), urea and creatinine, creatine kinase (CK), and creatine kinase $\mathrm{MB}(\mathrm{CK}-\mathrm{MB})$ were measured preoperatively, at preoperative time 0 , and postoperatively on days 1,2 , and 3 . Cardiac troponin (cTn-T) was measured preoperatively, and at 12 and 24 hours postoperatively in all cases.

Follow-up of cardiac rhythm and arrhythmia: Patients were monitored during the preoperative period and for at least 24 hours postoperatively. The rhythm follow-up of cases was confirmed by ECG at 0,6 , and 12 hours postoperatively, as well as on postoperative days 1, 2, and 3 .
Cases of ventricular tachycardia were medicated if they caused multifocal or hypertensive at a frequency of more than 10 per minute. Bigeminal and trigeminal rhythms and ventricular early beats that persisted long less $30 \mathrm{sec}-$ onds and that did not include the properties mentioned above were not medicated. In the case of supraventricular arrhythmia, if the ion balance and $\mathrm{K}^{+}$levels became normal but there was fast ventricular response AF, speed-limiting anti-arrhythmic agents were used.

Exclusion criteria for this study were the following: Preoperative renal insufficiency, requirement of a second openheart operation, left ventricular aneurism, additional cardiac pathology, and ischemia at the beginning of the operation (angina and ST alterations), off-pump CABS, and single-vessel disorders.

\section{Results and discussion}

The groups were created based on several variables such that they would not have significant differences in their demographic or preoperative profiles. The groups did not show a statistical difference in their mean left ventricle ejection fraction $(\mathrm{EF})(\mathrm{p}>0.05)$ (Table 1).

LIMA was used for LDA bypass in all patients. The radial artery was used for two patients, while all other anastomo- 
ses were performed using vena saphena grafts. The mean number of grafts used was $3.1 \pm 1.2$ in Group 1, $3.2 \pm 1.4$ in Group 2 and $3.1 \pm 1.4$ in Group 3, and these means were not significantly different. No significant difference was observed between groups based on mean cross clamp duration, perfusion duration, or use of inotropics. Similarly, mean transfusion amount, duration of intubation, duration of stay in the intensive care unit, and overall length of hospital stay did not differ significantly between the groups (Table 2).

Pre- and postoperative magnesium levels did not differ between the three groups. In Group 1, all the measured values showed a significant increase due to magnesium sulphate prophylaxis treatment during the postoperative period (day 0, $\mathrm{p}=0.001$; day $1, \mathrm{p}=0.02$; day 2, $\mathrm{p}=0.02$; day $3, \mathrm{p}<0.05$ in other groups). However, a decrease was observed in the level of magnesium following CABG during the preoperative period. Potassium and calcium levels were similar in both groups for in all measurements taken to assess whether replacement therapy was needed (Table 3).

Values of CK-MB and cardiac troponin t (cTnT) did not increase significantly for either group during the postoperative period (Table 4).

When postoperative arrhythmias were investigated, the total arrhythmia count of all patients was 25 (19.5\%). Of these, $17(13.35 \%)$ were supraventricular, and eight (6.25\%) were ventricular. All the cases of supraventricular arrhythmia involved atrial fibrillation, and two patients in the magnesium group showed pre-POAF atrial extrasystoles. No ventricular arrhythmia was detected in the amiodarone group. Arrhythmias in the form of extrasystoles were seen in eight patients of the magnesium group. When the arrhythmias were more than 10 per minute, lidocaine and metoprolol were administered. All eight cases were detected at the end of the first dose of antiarrhythmic treatment. These cases were given additional postoperative treatment of metoprolol (50 mg/day).

The AF that occurred postoperatively in the magnesium group was treated with amiodarone infusion $(900 \mathrm{mg} /$ day loading, $600 \mathrm{mg} /$ day oral continuation), and all patients recovered normal sinus rhythm. In the amiodarone prophylaxis group, patients were given magnesium ( $3 \mathrm{~g} /$ day), although two of seven patients (28.5\%) recovered normal sinus rhythm, while the other five $(71.5 \%)$ remained at $\mathrm{AF}$. These latter patients continued to receive amiodarone treatment, and no additional anti-arrhythmic medication was given. On average, patients recovered normal sinus rhythm by postoperative day 6 (Table 5).

\section{Discussion}

AF is an undesired but frequent complication of CABG observed in $10-40 \%$ of cases. It prolongs a patient's stay in the intensive care unit or hospital, and it disturbs a

Table 2: Preoperative and postoperative patient data.

\begin{tabular}{|c|c|c|c|c|}
\hline & Group I & Group 2 & Group 3 & $P$ \\
\hline LIMA usage & $64(100 \%)$ & $64(100 \%)$ & $64(100 \%)$ & NS \\
\hline Saphenous graft usage & 134 & 138 & 140 & NS \\
\hline Radial artery usage & $\mathrm{I}(\mathrm{I} .5 \%)$ & $\mathrm{I}(\mathrm{l} .5 \%)$ & - & NS \\
\hline Mean number of grafts & $3.1 \pm 1.2$ & $3.2 \pm 1.4$ & $3.1 \pm 1.4$ & NS \\
\hline Blood transfusion (units) & $2 \pm 1.5$ & $2 \pm 1.8$ & $2 \pm 1.8$ & NS \\
\hline Duration of intubation (hours) & $16.6 \pm 3.3$ & $15.2 \pm 3.2$ & $14.4 \pm 3.5$ & NS \\
\hline Duration of stay in intensive care unit & $50.3 \pm 5.3$ & $49.2 \pm 2.4$ & $50 \pm 5.5$ & NS \\
\hline Discharge time (days) & $7 \pm 1$ & $8 \pm 2$ & $7 \pm 1$ & NS \\
\hline Inotrope support & $24(37.5 \%)$ & $20(31.2 \%)$ & $24(37.5 \%)$ & NS \\
\hline Cross aortic clamp time (min) & $82 \pm 26$ & $85 \pm 22$ & $80 \pm 25$ & NS \\
\hline Perfusion time (min) & $104 \pm 44$ & $106 \pm 30$ & $100 \pm 41$ & NS \\
\hline
\end{tabular}

NS, not significant $(p>0.05)$. 
Table 3: Magnesium values of patients

\begin{tabular}{|c|c|c|c|c|c|}
\hline & & Group I & Group 2 & Group 3 & $P$ value \\
\hline \multirow[t]{6}{*}{ Magnesium (mg/dL) } & Preoperative & $1.9 \pm 0.3$ & $1.9 \pm 0.2$ & $2.1 \pm 0.3$ & NS \\
\hline & Perioperative & $1.7 \pm 0.2$ & $1.7 \pm 0.3$ & $1.8 \pm 0.3$ & NS \\
\hline & $0 *$ & $3.6 \pm 0.4$ & $1.5 \pm 0.2$ & $1.8 \pm 0.3$ & $0.00 I^{* *}$ \\
\hline & $I^{*}$ & $3.1 \pm 0.7$ & $1.6 \pm 0.2$ & $1.7 \pm 0.3$ & $0.02 * *$ \\
\hline & $2^{*}$ & $3.0 \pm 0.6$ & $1.6 \pm 0.3$ & $1.7 \pm 0.3$ & $0.02 * *$ \\
\hline & $3 *$ & $2.9 \pm 0.6$ & $1.7 \pm 0.2$ & $1.8 \pm 0.3$ & $0.04^{* *}$ \\
\hline
\end{tabular}

*Postoperative days; ** Significant (Difference between Group I and other groups). NS, not significant ( $p>0.05$ ).

patient's comfort. In addition, AF postpones full recovery after CABG. Thus, many drugs have been used prophylactically in order to prevent POAF: beta-blockers, calcium channel blockers, magnesium sulphate, and amiadarone. All of these drugs have different indications or counter indications [2-4].

Reducing the frequency of arrhythmia of a patient after CABG reduces both the duration of hospitalization and medical costs. Studies have shown that $25-30 \%$ of the patients had temporary supraventricular arrhythmia attacks despite using $\beta$-blockers. As is widely known, $\beta$ blockers are not indicated for those with poor ventricle function who frequently demonstrate arrhythmia. Instead, amiodarone is recommended for these patients $[4]$.

However, the sufficiency and reliability of amiodarone in preventing arrhythmia is controversial. Oral amiodarone is known to be insufficient for preventing postoperative arrhythmia, but sometimes the preoperative loading dose can prove sufficient. Amiodarone given during the preoperative period has been reported to react with anesthetic agents and cause pulmonary dysfunction, hypotension, hepatic dysfunction, and low heart flow. However, Daoud et al. have reported that preoperative amiodarone use does not increase the risk of postoperative mortality and morbidity $[4,5]$. Similarly, we did not observe any side effects in the amiodarone group in the present study. According to our observations, both drugs are safe.

Our results indicate that amiodarone is significantly more effective than magnesium sulphate in treating total arrhythmia. However, this may be because the ventricular extrasystoles frequently disappear in the absence of any medication. The two groups showed no differences in the rate of recovery from supraventricular arrhythmia.

Table 4: Enzyme values of patients.

\begin{tabular}{|c|c|c|c|c|c|}
\hline & & Group I & Group 2 & Group 3 & $P$ value \\
\hline \multirow[t]{4}{*}{ CK-MB (U/L) } & Preoperative & $29 \pm 2.5$ & $17 \pm 2.1$ & $17 \pm 2.5$ & NS \\
\hline & $12 \mathrm{hr}$ & $53 \pm 4.1$ & $108 \pm 5.5$ & $83 \pm 3.7$ & NS \\
\hline & $24 \mathrm{hr}$ & $74 \pm 3.6$ & $77 \pm 3.7$ & $63 \pm 4.1$ & NS \\
\hline & 3 day & $42 \pm 2.3$ & $47 \pm 3.2$ & $44 \pm 2.3$ & NS \\
\hline \multirow[t]{4}{*}{$\mathrm{cTn}-\mathrm{T}(\mathrm{ng} / \mathrm{mL})$} & Preoperative & $1.23 \pm 0.2$ & $1.91 \pm 0.3$ & $\mathrm{I}, 6 \mathrm{I} \pm 0.4$ & NS \\
\hline & $12 \mathrm{hr}$ & $2.11 \pm 0.3$ & $2.45 \pm 0.4$ & $2,53 \pm 0.3$ & NS \\
\hline & $24 \mathrm{hr}$ & $1.31 \pm 0.4$ & $1.54 \pm 0.2$ & $1,27 \pm 0.4$ & NS \\
\hline & 3 day & $0.9 \pm 0.2$ & $0.7 \pm 0.1$ & $0.8 \pm 0.2$ & NS \\
\hline
\end{tabular}

CK-MB, creatine kinase-MB; $c T n-T$, cardiac troponin-T; NS, Not Significant $(p>0.05)$. 
Table 5: Postoperative arrhythmia observed in the patient sample.

\begin{tabular}{|c|c|c|c|c|c|}
\hline & & Group I $(n=64)$ & Group $2(n=64)$ & Group $3(n=64)$ & $P$ value \\
\hline Postoperative arrhythmia & & $18(28.1 \%)$ & 7 (10.9\%) & $30(46 \%)$ & $0.015^{*}$ \\
\hline \multirow[t]{3}{*}{ Supraventricular arrhythmia } & & $10(16.7 \%)$ & $7(10.9 \%)$ & $20(31 \%)$ & NS \\
\hline & Atrial extrasystole & $2(3.3 \%)$ & 0 & 0 & NS \\
\hline & Atrial fibrillation & $10(16.7 \%)$ & $7(10.9 \%)$ & $20(37.3 \%)$ & NS \\
\hline AF exit time (hours) & & $49 \pm 15$ & $123 \pm 27$ & $48 \pm 17$ & $0.026 *$ \\
\hline \multirow[t]{2}{*}{ Ventricular arrhythmia } & & $8(12.5 \%)$ & 0 & $10(\% \mid 5)$ & $0.001 *$ \\
\hline & Ventricular extrasystole & $8(12.5 \%)$ & 0 & $10(\% \mid 5)$ & $0.001 *$ \\
\hline
\end{tabular}

* Significant (Difference between Group I and Group 2).

Magnesium is a cation that functions by lengthening the refractory period at the atrioventricular node. Thus, magnesium likely has an important role in preventing and treating atrial fibrillation, especially considering that serum magnesium levels below $0.8 \mathrm{mmol} / \mathrm{L}$ trigger atrial fibrillation. Thus, dose loading with magnesium can prevent the arrhythmia caused by the postoperative decrease in this caution.

In our study we observed that the serum magnesium levels were low in the postoperative period, although never below $0.8 \mathrm{mmol} / \mathrm{L}[2]$.

Many comparative studies and meta-analyses have been published on this issue. In a meta-analysis evaluating atrial fibrillation after CABG, the frequency of POAF was determined to be $32.3 \%$. POAF is frequently concomitant with renal insufficiency and infection. In this meta-analysis, preoperative COPD and older age were determined to be risk factors for POAF. The investigators concluded that atrial fibrillation is an important complication of CABG, and they suggested preventing it by administering $\beta$ blockers and ACE inhibitors [6].

Çağlı et al. performed a study that combined amiodarone and $\mathrm{MgSO}_{4}$, and they concluded that together these agents are tolerable and work more effectively in high-risk patients than they do on their own [7]. A different study showed that older age and lower magnesium plasma levels are the most important risk factors of POAF. This same study reported that amiodarone was effective for POAF, whereas magnesium prophylaxis had no effect [5-8]. In our study, we administered amiodarone to patients with AF despite magnesium prophylaxis; we administered amiodarone orally, following an initial loading dose.
Studies have examined the effects of medications other than prophylaxis following AF. Parenteral magnesium was reported to be superior to amiodarone in studies of acute atrial tachyarrhythmia [9]. Davey et al. have shown that magnesium sulphate slows the heart rate and prevents supraventricular arrhythmia. They also found that $\mathrm{AF}$ frequently returns to normal sinus rhythm in patients treated with magnesium sulphate. Lastly, they reported that magnesium-related hypotension and bradycardia are potential risk factors for $\mathrm{AF}[10]$.

In a meta-analysis evaluating eight different clinical studies, the use of different doses of magnesium sulphate, placebo, amiodarone, and diltiazem following atrial fibrillation was examined. During the first hour following its application, magnesium was found to be superior to other anti-arrhythmics for controlling ventricular speed (patients with a heartbeat of less than 100/min). Magnesium was also significantly more effective than placebo or diltiazem for restoring normal sinus rhythm within the first 15 hours. As a result, magnesium sulphate effectively controls heart rhythm following AF [11]. In another study, magnesium was found to be effective at preventing postoperative ventricular arrhythmia in a dose-dependent manner [12].

\section{Conclusion}

The types of patients examined in this study require treatment for their atrial fibrillation. Our study shows that both amiodarone and magnesium sulphate work safely and sufficiently rapidly for this purpose. Our clinic already uses amiodarone frequently, and this study shows that magnesium is also effective at treating postoperative arrhythmia. In fact, using magnesium may avoid low postoperative levels of magnesium and its concomitant 
side effects, as well as postoperative atrial fibrillation. Thus, we suggest routine magnesium sulphate administration in patients undergoing open-heart surgery.

\section{Competing interests}

The authors declare that they have no competing interests.

\section{Authors' contributions}

OT: Designed the study, coordinated it, and performed statistical analysis. SD: Conceived the study and participated in its design. HA: Designed the study and performed the echocardiographic study and performed statistical analysis. SKT: Designed the study and performed the echocardiographic study. KH: Performed biochemical analysis. OS: Performed statistical analysis. AO: Coordinated the study.

\section{References}

I. Banach M, Rysz J, Drozdz JA, Okonski P, Misztal M, Barylski M, Irzmanski R, Zaslonka J: Risk factors of atrial fibrillation following coronary artery bypass grafting: a preliminary report. Circ J 2006, 70(4):438-4I.

2. Toraman F, Karabulut EH, Alhan C, Dagdelen S, Tarcan S: Magnesium infusion dramatically decreases the incidance of atrial fibrillation after coronary artery bypass grafting. Ann Thorac Surg 200I, 72:1256-62.

3. Heintz KM, Hollenberg SM: Perioperative cardiac issues: postoperative arrhythmias. Surg Clin North Am 2005, 85(6): I I 03-I4.

4. Daoud EG, Strickberger SA, Man KC, Goyal R, Deeb GM, Bolling SF, Pagani FD, Bitar C, Meissner MD, Morady F: Preoperative amiodarone as prophylaxis against atrial fibrillation after heart surgery. N Engl J Med 1997, 337(25): I785-9I.

5. Turkay C, Golbasi İ, Ak İ, Erbasan O, Mete A, Bayezid O: Koroner Bypass Cerrahisi Sonrası Profilaktik Amiodaronun Aritmiler ve Sol Ventrikül Fonksiyonlarına Etkisi. Turkish J Thorac Cardiovasc Surg 2000, 8(4):74I-744.

6. Mathew JP, Fontes ML, Tudor IC, Ramsay J, Duke P, Mazer CD, Barash PG, Hsu PH, Mangano DT: Investigators of the Ischemia Research and Education Foundation; Multicenter Study of Perioperative Ischemia Research Group. A Multicenter Risk Index for Atrial Fibrillation after Cardiac Surgery. JAMA 2004, 29I(I4): I720-1729.

7. Cagli K, Ozeke O, Ergun E, Budak B, Demirtas E, Birincioglu CL, Pac M: Effect of Low-Dose Amiodarone and Magnesium Combination on Atrial Fibrillation After Coronary Artery Surgery. J Cardiac Surg 2006, 2 I (5):458.

8. Treggiari-Venzi MM, Waeber JL, Perneger TV, Suter PM, Adamec R, Romand JA: Intravenous amiodarone or magnesium sulphate is not cost-beneficial prophylaxis for atrial fibrillation after coronary artery bypass surgery. $\mathrm{Br} J$ Anaesth 2000, 85(5):690-695.

9. Moran JL, Gallagher J, Peake SL, Cunningham DN, Salagaras M, Leppard $P$ : Parenteral magnesium sulfate versus amiodarone in the therapy of atrial tachyarrhythmias: a prospective, randomized study. Crit Care Med 1995, 23(I I):1816-24.

10. Davey MJ, Teubner D: A randomized controlled trial of magnesium sulfate in addition to usual care, for rate control in atrial fibrillation. Ann Emerg Med 2005, 45(4):347-53.

II. Onalan O, Crystal E, Daoulah A, Lau C, Crystal A, Lashevsky I: Metaanalysis of magnesium therapy for the acute management of rapid atrial fibrillation. Am J Cardiol 2007, 99(I2): 1726-32.

12. Kiziltepe U, Eryilmaz S, Sirlak M, Yazicioglu L, Kaya K, Durdu S, Eren NT, Tasoz R, Uysalal AA, Akalın $\mathrm{H}$ : The Use of Magnesium as an Antiarrthymic Agent for The Patients Undergoing Open Heart Surgery: The Effect Of Blood Levels. Turkiye Klinikleri J Cardiovascular Surg 200 I, 2:113-119.
Publish with Biomed Central and every scientist can read your work free of charge

"BioMed Central will be the most significant development for disseminating the results of biomedical research in our lifetime. "

Sir Paul Nurse, Cancer Research UK

Your research papers will be:

- available free of charge to the entire biomedical community

- peer reviewed and published immediately upon acceptance

- cited in PubMed and archived on PubMed Central

- yours - you keep the copyright
BioMedcentral 